\title{
OPEN Experimental study on the bearing capacity of PZ shape composite dowel shear connectors with elliptical holes
}

\author{
Pingming Huang, Junlong $\mathrm{He}^{\varpi}$, Fanlei Kong ${ }^{\varpi}$, Kuihua Mei \& Xiaolong Li
}

The push-out test was carried out in order to study the shear performance of perfobond ribs (PBL) and puzzle (PZ) shape composite dowel shear connectors which are used in corrugated steel-concrete composite bridge decks. By considering the influencing factors of transversal reinforcement, elliptical holes and bonding friction forces, eight specimens were designed and prepared. The load-slip curves were obtained, and the static mechanical properties, including bearing capacity, slip, shear stiffness, and ductility factor, were analyzed. The formula of bearing capacity and load-slip curve were proposed. The results showed a clear deformation of the transversal reinforcement of both the two types of shear connectors. The dominating failure mode of both the shear connectors was the double plane shearing of the concrete dowel. The load-slip curves of the two types of shear connectors followed the same trend. The PZ shape composite dowel performed better in ultimate bearing capacity, ductility, and shear stiffness than the PBL shear connector. Elliptical holes in a PZ shape composite dowel significantly increased the ultimate bearing capacity. The shear stiffness increased with transversal reinforcement and reduced with elliptical holes. For PBL shear connectors, the strain change in the $\mathrm{C} 1$ area near the loading point was most apparent. While, the $\mathrm{A} 1$ and $\mathrm{B} 1$ areas were stress concentration locations for PZ shape composite dowel shear connectors. The two formulas were in good agreement with the test results.

Recently, steel-concrete composite bridge decks have become more widely used. Figure 1 shows a new kind of steel-concrete composite bridge deck slab. It is composed of corrugated steel sheets, concrete, and shear connectors $^{1-3}$. Corrugated steel sheeting can be prefabricated and serve as stay-in-place (SIP) steel forms when concrete is casted on-site. Compared with reinforced concrete bridge decks, it has the advantages of high bearing capacity and fast construction ${ }^{4,5}$.

The steel and concrete members in the composite structure work together through the shear connector. Perfobond rib connector (PBL) is the most commonly used shear connector for creating a composite action. Di studied the mechanical properties and bearing mechanism of the large PBL connectors with strong confinement ${ }^{6}$. The results showed a difference of $191 \%$ in the shear stiffness of connectors with different shapes. The interaction effects in a PBL within a connector group was investigated by Guan and practical formulas were proposed for the PBL group prediction ${ }^{7}$. In another study, Yang studied the mechanical properties of PBL shear connectors under different bearing types. By taking the contribution of end concrete into account, the authors presented a formula for bearing capacity calculation ${ }^{8}$. Zhang evaluated the fatigue life of the PBL shear connector group and reported that the degree of fatigue damage in each layer of the shear connector is sensitive to the upper load level ${ }^{9}$. However, PBL shear connectors are not suitable for this type of bridge deck, due to their structural limitations.

Puzzle (PZ) shape composite dowel is a half-open shear connector. During construction, the transversal reinforcement is easy to install and put into the designated position. Moreover, its bearing capacity is better than the PBL shear connectors, and exhibiting good anti-fatigue performance as well ${ }^{10-13}$. Researchers have carried out a series of static tests and theoretical studies on PZ shape composite dowel shear connectors in recent years. Shear design approaches for pry-out failure have been proposed by Classen ${ }^{14,15}$, while other researchers have focused on modeling the steel failure in thin UHPC elements ${ }^{16}$. Lorenc conducted full-scale push-out tests to study how the steel thickness, grade, and dowel size can affect the bearing capacity ${ }^{17}$. The results proved the plastic deformation of steel dowel to be the main factor causing concrete failure. Finite element (FE) method 


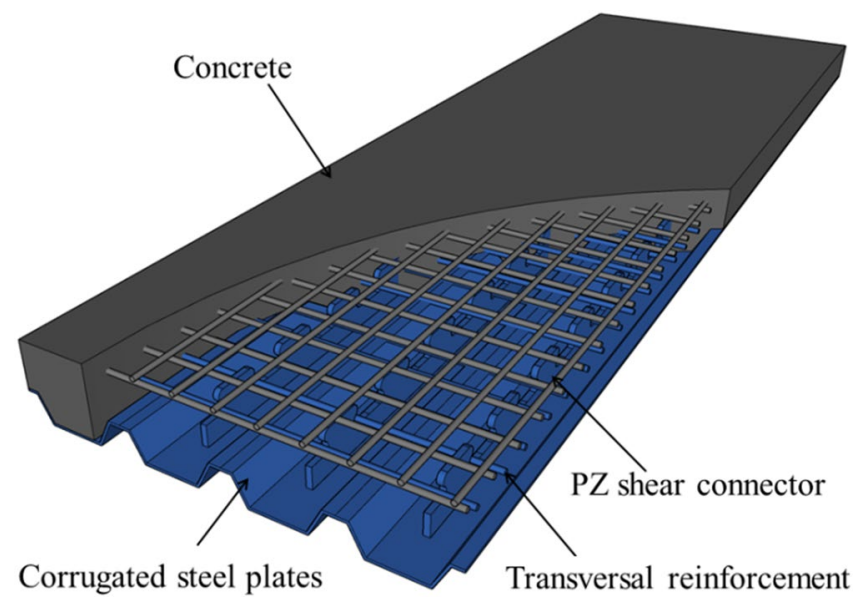

Figure 1. Schematic diagram of corrugated steel-concrete composite bridge decks.

\begin{tabular}{|l|l|l|l|}
\hline Specimen & Hole diameter $(\mathbf{m m})$ & Concrete strength $(\mathrm{MPa})$ & Diameter of transversal reinforcement $(\mathbf{m m})$ \\
\hline PBL-1 & 50 & 54.3 & - \\
\hline PBL-2 & 50 & 53.6 & 16 \\
\hline PBL-3 & 50 & 54.1 & 16 \\
\hline
\end{tabular}

Table 1. Parameters of PBL shear connector specimens.

\begin{tabular}{|l|l|l|l|l|}
\hline Specimen & Concrete strength $(\mathbf{M P a})$ & $\begin{array}{l}\text { Diameter of transversal } \\
\text { reinforcement }(\mathbf{m m})\end{array}$ & $\begin{array}{l}\text { Ellipse dimensions (a and } \\
\text { b) }(\mathbf{m m})\end{array}$ & Steel dowel base height $(\mathbf{m m})$ \\
\hline PZ-1 & 53.8 & $2 \mathrm{~d} 16$ & $30 / 15$ & 90 \\
\hline PZ-2 & 52.7 & - & $30 / 15$ & 90 \\
\hline PZ-3 & 53.1 & $2 \mathrm{~d} 16$ & - & 90 \\
\hline PZ-4 & 54.2 & $2 \mathrm{~d} 16$ & - & 120 \\
\hline PZ-5 & 53.5 & $2 \mathrm{~d} 16$ & $40 / 20$ & 120 \\
\hline
\end{tabular}

Table 2. Parameters of PZ shape shear connector specimens.

is also used to analyze the failure mechanism of shear connectors ${ }^{18}$. Lacki optimized the shape of composite dowel shear connector used in a composite structure ${ }^{19}$. A parametric study of steel-concrete composite beam with composite dowel connectors was done by Derlatka and the best solution for composite dowel beam was selected from seven variants. Additionally, using the FE method makes it possible to investigate the influence of mechanical loads on the strains and stresses in the floor beam ${ }^{20}$.

However, PZ shape composite dowel shear connectors are mainly used in prefabricated composite beams in some European countries ${ }^{21-26}$, and these research studies are also based on composite beams. The related research and practical applications of corrugated steel-concrete composite bridge decks have not well-documented. Due to the large size and thickness of the shear connectors in composite beams and the effect of stirrups, the standard calculation of bearing capacity is not applicable to this composite bridge deck.

This study mainly aimed to evaluate the applicability of PZ shape composite dowel shear connectors with small size and weak constraints in corrugated steel-concrete composite bridge decks. This paper empirically studied the shear behavior of the connectors with elliptical holes, and applied push-out tests to investigate the static performance of PZ shape composite dowel shear connectors. Accordingly, several groups of PBL shear connectors were compared. The effects of different parameters such as transversal reinforcement, elliptical holes, and bonding friction on the bearing capacity, slip, shear stiffness, ductility, and strain of shear connectors were also investigated. Considering the practical engineering applications, the bearing capacity and load-slip formulas of PZ shape composite dowel shear connectors with elliptical holes were devised, which provides a foundation for the design of shear connectors in corrugated steel-concrete composite bridge deck. This research can pave the path for the generalization and application of PZ shape composite dowel shear connectors in China.

\section{Experimental program}

Design of specimens. In this paper, eight specimens were designed for push-out tests. The main parameters of each specimen are shown in Tables 1 and 2. In the specimens, the thickness of corrugated steel sheeting is $6 \mathrm{~mm}$, the shear connector thickness is $14 \mathrm{~mm}$, and the materials for both are Q345 qE. The concrete dowel 


\section{Localization and Numbering of Strain Gauges}

$\square \mathrm{A} 1-\mathrm{A3} \square \mathrm{B} 1-\mathrm{B3}=\mathrm{C} 1=\mathrm{D} 1-\mathrm{D3}$

(a)
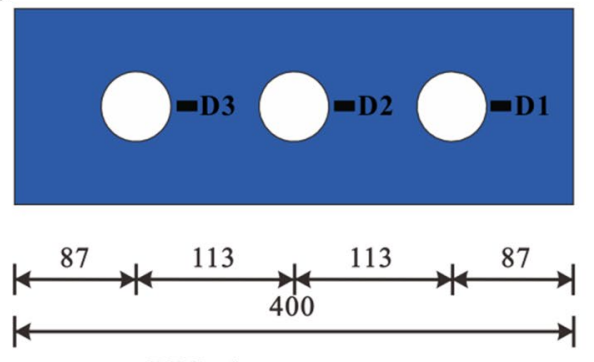

PBL shear connector (b)
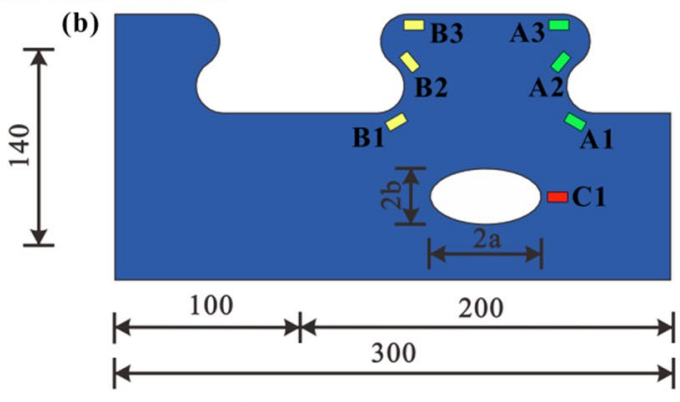

PZ shape shear connector

Figure 2. Geometry of PBL and PZ shear connectors.

transversal reinforcement is a HRB400 bar with a diameter of $16 \mathrm{~mm}$. The strength of the concrete is C50 grade. A single layer of reinforced mesh is arranged $30 \mathrm{~mm}$ away from the upper surface of the concrete. The reinforcement is HRB400 grade. The diameter of the reinforcement is $12 \mathrm{~mm}$. The spacing between the reinforcement is $100 \mathrm{~mm}$. In Table 2, a and b refer to the major and minor semi-axes of the ellipse, respectively. Geometry of the PBL and PZ shape composite dowel shear connectors are shown in Fig. 2. Structural dimensions of the push-out specimens are shown in Fig. 3.

During the production of the specimen, a foam plate with a pad length of $50 \mathrm{~mm}$ at the bottom of the shear connector was used to eliminate the pressure effect of the concrete. With the exception of PBL-2, all other specimens were smeared with butter on the contact surface between the shear connector and concrete to eliminate the influence of a bonding force between the steel plate and concrete. Figure 4 shows the specimens before casting concrete.

Measurement content and point arrangement. The measured parameters included the strain of the surface concrete, shear connector, and transversal reinforcement; the relative slip of the concrete and shear connector; and the load value. Figure 2 shows strain gauge layout. In this figure, A1-3, B1-3, C1 and D1-3 are the numbers of strain gauges. The relative slip was obtained by using two displacement transducers, and the strain was obtained via the static and dynamic data acquisition systems. The acquisition frequency was $1 \mathrm{~Hz}$. Load values were obtained directly from the computer.

Test program. The loading device for this test is an electro-hydraulic servo press controlled by a $200 \mathrm{t}$ microcomputer. Figure 5 schematically shows the load setup. The specimens were first placed on the loading device platform and then were subjected to the load by the upper beam. Figure 6 shows the loading setup. The test was preloaded three times before formal loading to eliminate inelastic deformation and to verify normal operation of the acquisition system. Formal loading was divided into two stages: load control and displacement control. The loading rate is $2 \mathrm{kN} / \mathrm{s}$ under load control. The loading rate is $0.2 \mathrm{~mm} / \mathrm{s}$ under displacement control.

The mechanical properties of the main materials were tested before the push-out test. Tables 1 and 2 show the strength of the concrete, and the test results of the transversal reinforcement and steel plate are presented in Table 3 .

\section{Results and discussion}

Failure mode. At initial loading, there was no obvious slip. With the increase of load, the displacement transducers showed slip of the steel plate and concrete, but the specimens showed no obvious visible changes. After loading to the limit load of $80 \%$, the slip visibly increased. Firstly, several vertical micro-cracks were observed at the bottom of the specimen, which extended from the inside of the specimen. Subsequently, the crack continued to expand and gradually widened. At the same time, cracks appeared on the sides and top of the concrete. Finally, the top and bottom cracks were connected vertically. The failures exhibited are all concrete shear failure. The concrete at the bottom of the specimens had different degrees of spalling. The sound of concrete cracking was noted during testing. For the specimens without transversal reinforcement, the load changed clearly in the descending section. Figure 7 shows an example of the concrete cracks in a specimen during testing.

Figures 8 and 9 illustrate some examples of deformed specimens with PBL and PZ shape shear connectors after breaking, respectively. It can be seen from the figures that no clear deformation or failure was observed at the round holes of the PBL shear connector. Similarly, the steel dowels and elliptical holes of the PZ shape composite dowel shear connector showed no obvious deformation. However, the transversal reinforcement of the two shear connectors was clearly deformed, but it was not cut. This is because the specimen has large slip, so the transversal reinforcement was squeezed to the edge of the round hole and steel dowel, and the concrete and dowel bear the shear force together. By comparing the two different shear connectors, since in the PBL connectors, the transversal reinforcement was closer to the round holes, the deformation of the transversal reinforcement in the $\mathrm{PBL}$ shear connector was more obvious than that of the PZ shape one. Double plane shearing of the concrete dowel was the dominant failure mode in both connector types. 


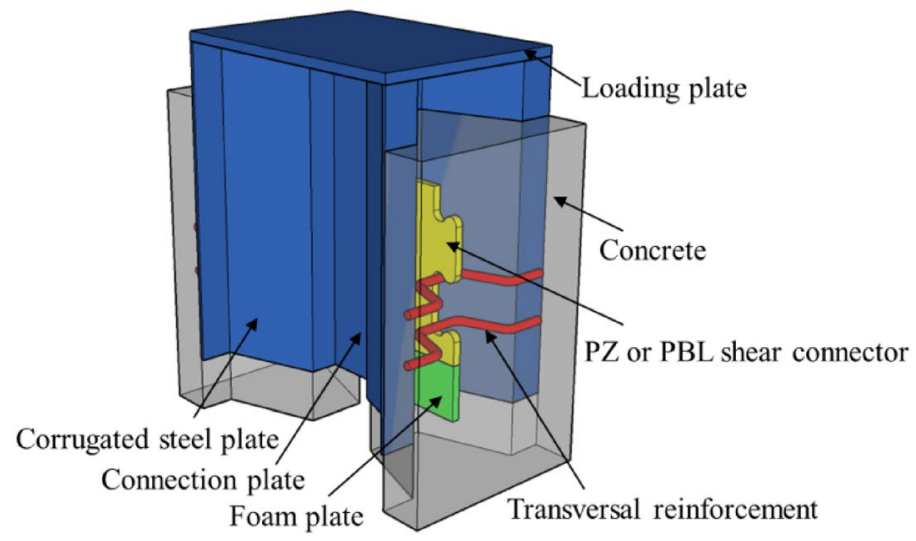

(a) Schematic diagram of specimens

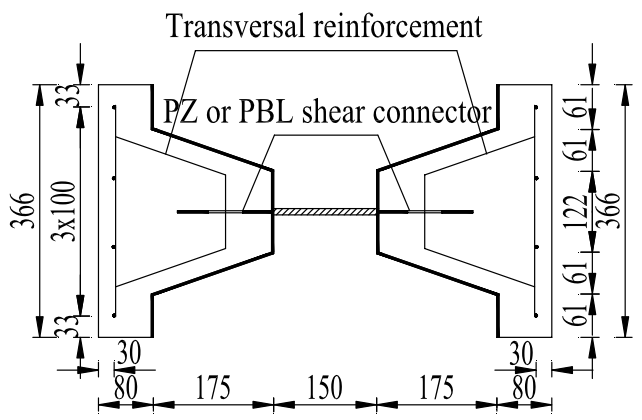

(b) Top view

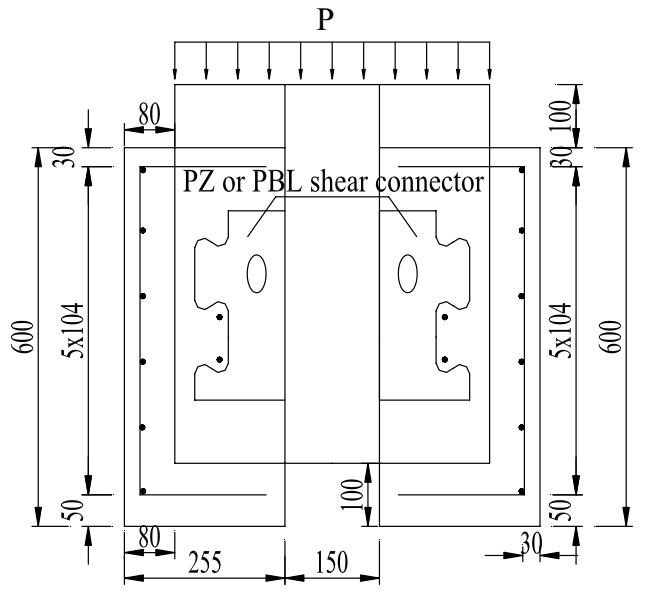

(c) Front view

Figure 3. Structural dimensions of push-out specimens.

Load-slip curves and static mechanical property indexes. The load-slip curves and static mechanical property indexes of the test specimens are shown in Fig. 10 and Table 4, respectively. The main static mechanical property indexes of shear connectors are as follows: bearing capacity limit value $P_{u}$, characteristic bearing capacity $P_{R k}$, bearing capacity design value $P_{R d}$, limiting slip $\delta_{u}$, design slip $\delta_{d}$, shear stiffness $K_{s}$, and ductility factor $D_{c}$. $P_{u}$ is the maximum bearing capacity of the shear connector. $P_{R k}$ is $0.9 P_{u}$, and $P_{R d}$ is $P_{R k}$ divided by the factor of $\gamma_{v}$, where $\gamma_{v}=1.25 . \delta_{u}$ is the maximum value of the slip amount corresponding to $P_{R k}, \delta_{d}$ is the slip amount corresponding to $P_{R d}$. $K_{s}$ is the slope of the line between the origin and $P_{R d}$ on the load-slip curves. $D_{c}$ 


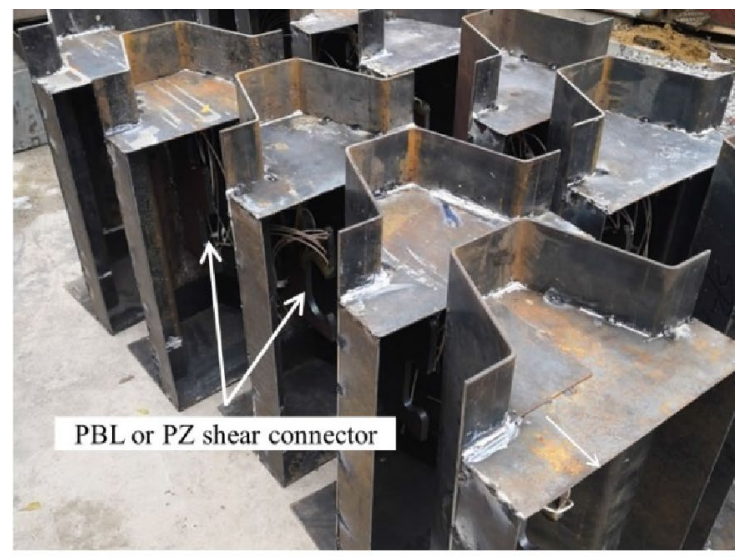

(a) Formwork of precast slab

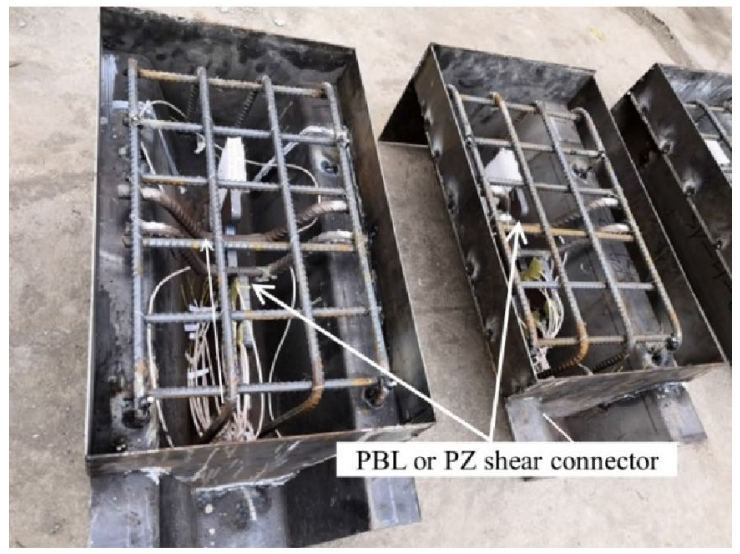

(b) Reinforcement of precast slab

Figure 4. Specimens before casting concrete.

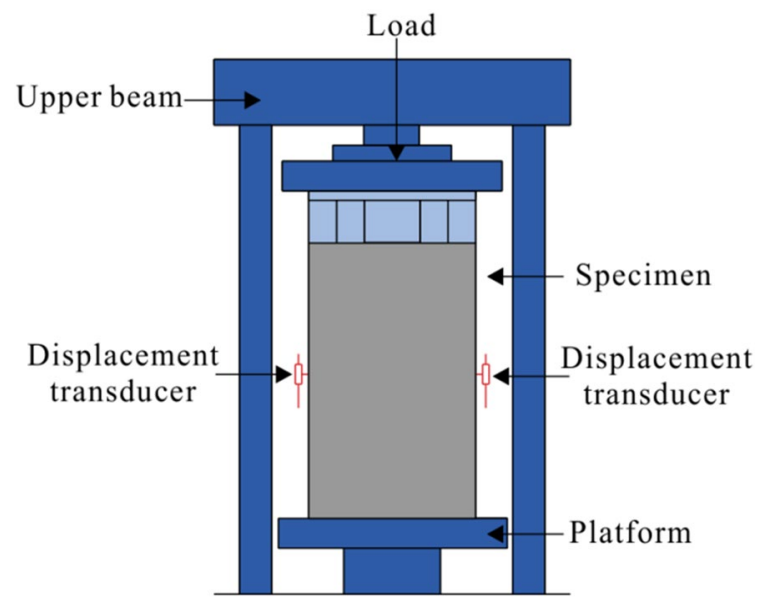

Figure 5. Schematic diagram of the load setup.

is the ratio of $\delta_{u}$ to $\delta_{d}{ }^{27}$. The values in Table 4 have been converted to the corresponding test values of a single hole and a single steel dowel.

Ultimate bearing capacity. The ultimate bearing capacity of PBL- 3 increased by $72.0 \%$ compared with that of PBL-1, and the ultimate bearing capacity of PZ-1 increased by $60.3 \%$ compared with that of PZ- 2 . The 


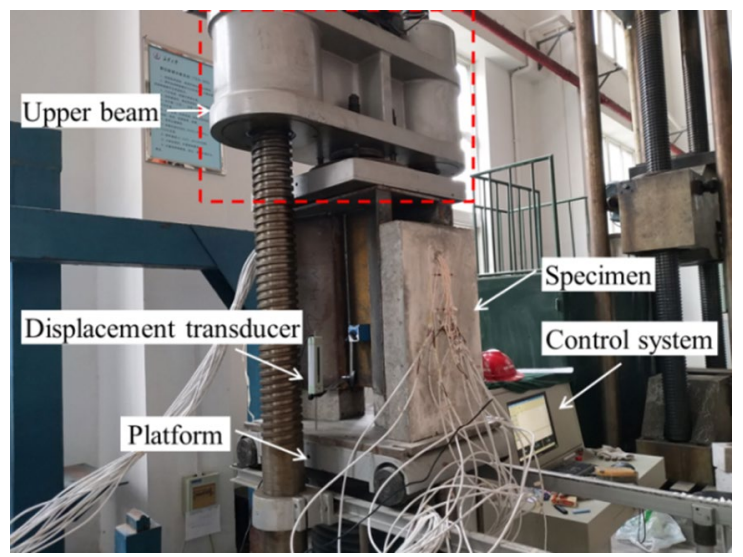

Figure 6. Load setup of specimens.

\begin{tabular}{|l|l|l|}
\hline Material & Yield strength (MPa) & Ultimate strength (MPa) \\
\hline Steel plate (Q345Qe) & 422.6 & 524.1 \\
\hline Transversal reinforcement (HRB400) & 446.0 & 604.8 \\
\hline
\end{tabular}

Table 3. Test results of material properties.

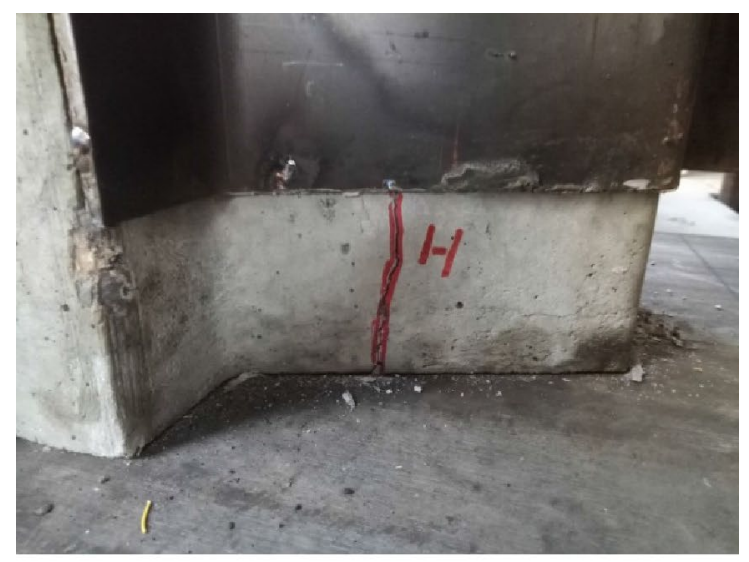

(a) Cracks at the bottom of specimens

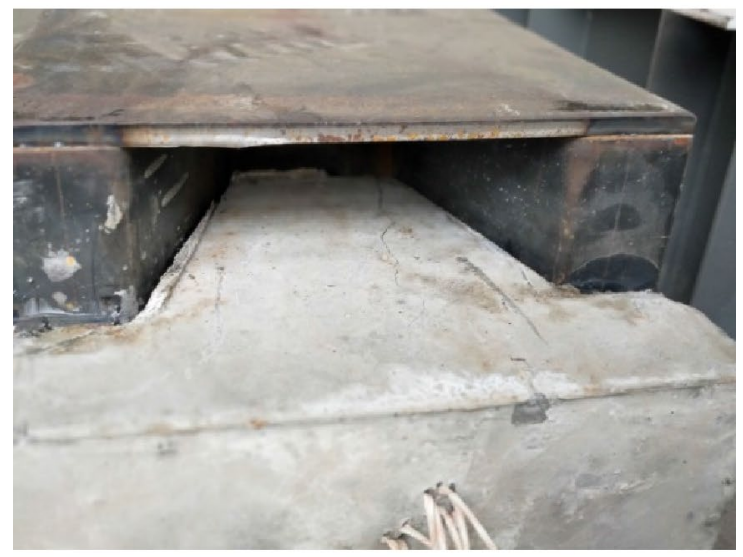

(b) Cracks at the top of specimens

Figure 7. Concrete cracks in a specimen during testing. 


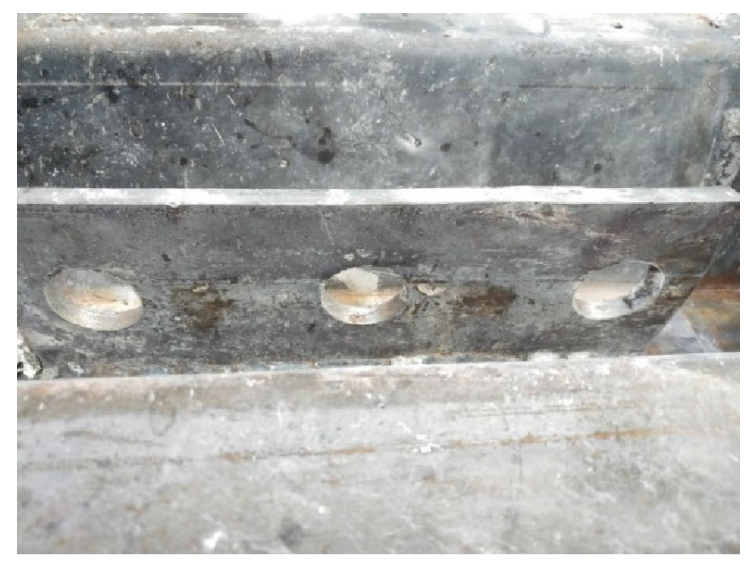

(a) Deformation of $\mathrm{PZ}$ shear connector

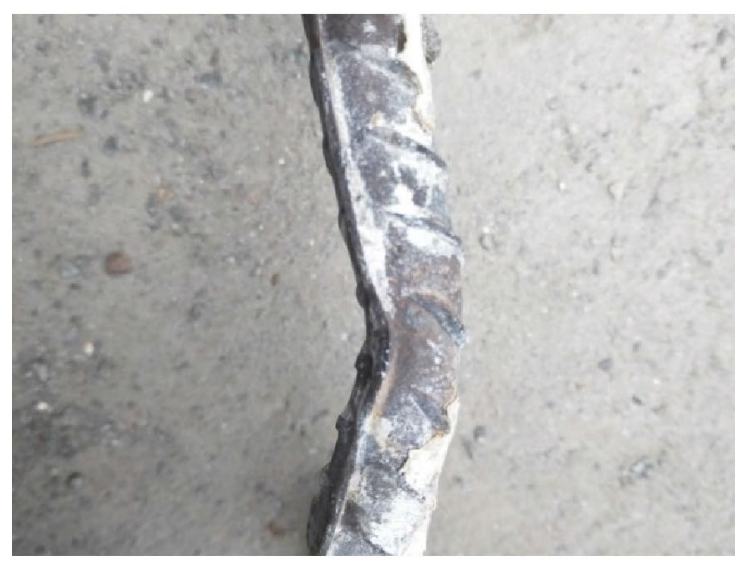

(b) Deformation of transversal reinforcement

Figure 8. A specimen with PBL shear connector after breaking.

only difference between PBL-3 and PBL-1 is that PBL-3 has transversal reinforcement. Likewise, the only difference between PZ-1 and PZ-2 is that PZ-1 has transversal reinforcement. It can be seen that transversal reinforcement can significantly improve the bearing capacity of the specimen.

The ultimate bearing capacity of PBL-2 was $19 \mathrm{kN}$ higher, or about $9 \%$ higher, than that of PBL-3. Therefore, the presence of a bonding force and friction force between the steel plate and concrete creates a measurable difference in shear properties. However, due to the complex working mechanisms and unpredictable performance of the bonds, it is usually considered as a safety measure and is not included in the calculation of the ultimate bearing capacity.

In order to compare the ultimate bearing capacity of PZ and PBL shear connectors, the shear connectors were converted into lengths of $400 \mathrm{~mm}$. The ultimate bearing capacity of PZ-3 is $65.6 \mathrm{kN}$ higher, or $11 \%$ higher, than that of PBL-3. The comparison between PZ-1 and PZ-3 shows that the ultimate bearing capacity of elliptical hole is about $95 \mathrm{kN}$. Thus, it can be shown that the ultimate bearing capacity of PZ-2 is about $188.8 \mathrm{kN}$ if no elliptical hole is opened. When an elliptical hole is not opened, and the length of shear connector is $400 \mathrm{~mm}$, the ultimate bearing capacity of PZ-2 increases by $28.4 \mathrm{kN}$, or $8.1 \%$, when compared with that of PBL-1. Therefore, the ultimate bearing capacity of the PZ shear connector is higher than that of PBL shear connector, with or without transversal reinforcement penetration.

The ultimate bearing capacity of PZ-3 increased by $14.4 \mathrm{kN}$, or $0.04 \%$, when compared with PZ- 4 . This shows that the ultimate bearing capacity decreases slightly with the increase of steel dowel height. The ultimate bearing capacity of PZ-1 increased by $95.2 \mathrm{kN}$, or $28.6 \%$, compared with that of PZ-3, and the ultimate bearing capacity of PZ-5 increased by $126.5 \mathrm{kN}$, or $38.0 \%$, compared with that of PZ-3. It can be seen that the bearing capacity can be improved by opening elliptic holes in the composite dowel shear connector.

Shear stiffness and ductility. It can be seen from Table 4 that the shear stiffness of the PZ shear connectors is greater than that of PBL shear connectors. By comparing PBL-3 with PBL-1, and PZ-1 with PZ-2, it is shown that transversal reinforcement can effectively improve the shear stiffness of shear connectors. The shear stiffness of PZ-5 is smaller than that of PZ-1. The shear stiffness of PZ-1 and PZ-5 are both smaller than that of PZ-3 and PZ-4. The results show that the shear stiffness of shear connectors will be reduced by opening elliptical holes, while the reduction degree with large holes is greater than that with small holes. Although opening ellipti- 


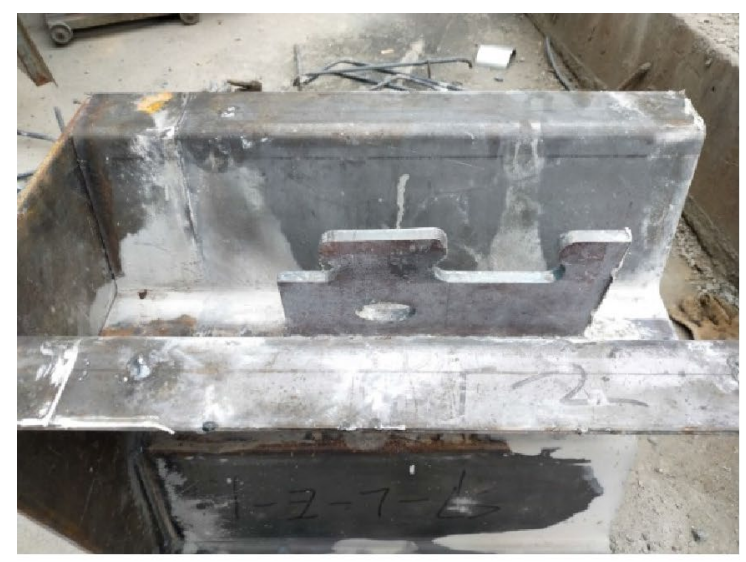

(a) Deformation of $\mathrm{PZ}$ shear connector

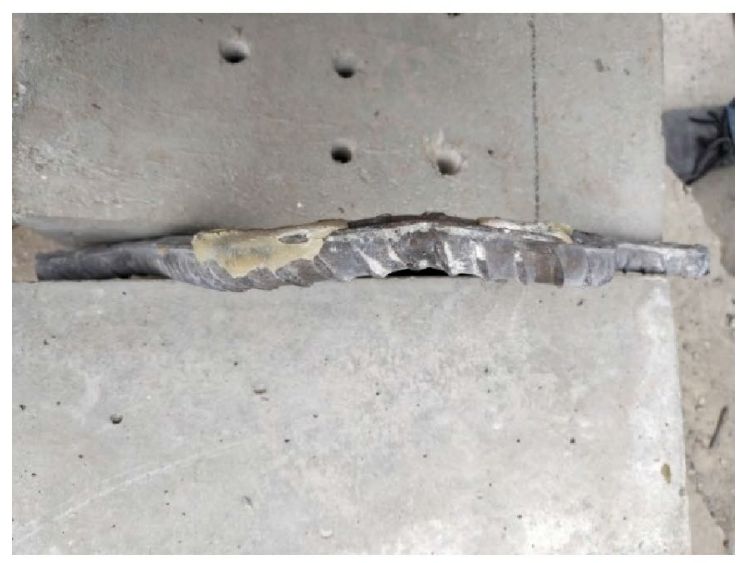

(b) Deformation of transversal reinforcement

Figure 9. A specimen with $\mathrm{PZ}$ shear connector after breaking.

cal holes can increase the bearing capacity of PZ shape composite dowel shear connectors, it can also reduce the shear stiffness. Therefore, the balance between the two should be fully considered in the design of shear connectors, and the size of elliptical holes cannot be increased without limit.

Ductility factor is also an important index to reflect the shear connector performance. Shear connectors should have good ductility when they are broken. In EN 1994-1-1, a minimum deformation capacity of $6 \mathrm{~mm}$ is demanded for ductile shear connectors ${ }^{28}$. The $\delta_{\mathrm{u}}$ values for PBL-1 and PZ-2 specimens were below $6 \mathrm{~mm}$, while it was above $6 \mathrm{~mm}$ for the other specimens. It is worth noting that the transversal reinforcement was the difference between specimens PBL-1 and PZ-2 and other specimens where these two samples had no transversal reinforcement. Therefore, it can be concluded that transversal reinforcement enhanced the ductility of shear connectors. Additionally, the ductility factor of PZ shear connectors was shown to be higher than that of PBL shear connectors, resulting in a higher ductility of $\mathrm{PZ}$ shear connectors.

Load-strain curves. The concrete surface showed no obvious visible strain. This is due to the gap between the top of the shear connector and the concrete surface, between which there are structural bars. The failure mode is not concrete pry-out. Therefore, the load-strain curves of the concrete are not listed in this paper. Figure 11 shows the load-strain curves of the steel dowels and the transversal reinforcement load-strain curves are depicted in Fig. 12.

As can be seen in Fig. 11, the load-strain curves of the two types of shear connectors have a linear relationship with the initial loading. For the PBL-1 specimen, when the load value was $490 \mathrm{kN}$, or about $0.7 P_{\mathrm{u}}$, the microstrain values at point $\mathrm{C} 1$ and $\mathrm{C} 3$ were about 303 and 110, respectively. The value at point $\mathrm{C} 1$ was about 2.8 times that of point C3. Regarding the PBL-2 specimen, the microstrain value at point $\mathrm{C} 1$ was about 1020 , which was about three times that of point C3, with a value of 340 , when the load value was $920 \mathrm{kN}$, or about $0.7 P_{\mathrm{u}}$. Likewise, at a load of $840 \mathrm{kN}$, or about $0.7 P_{\mathrm{u}}$, for the PBL-3 specimen, the microstrain value at point C1 (approximately 1140 ) was about three times that of point C3 (approximately 380). It can be concluded that for all the three PBL shear connectors, the most changes appeared in $\mathrm{C} 1$, which was the closest to the loading point, while the C3, the farthest area from the loading point, experienced the least significant changes. In all measuring points of $\mathrm{PZ}$ shear connectors, the A and B areas were under compressive and tensile stresses, respectively. The strain change 


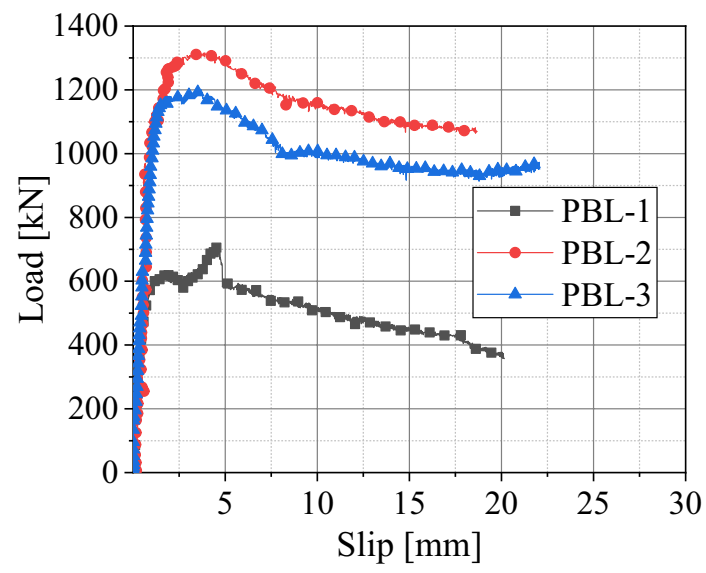

(a) Load-slip curves of PBL shear connectors

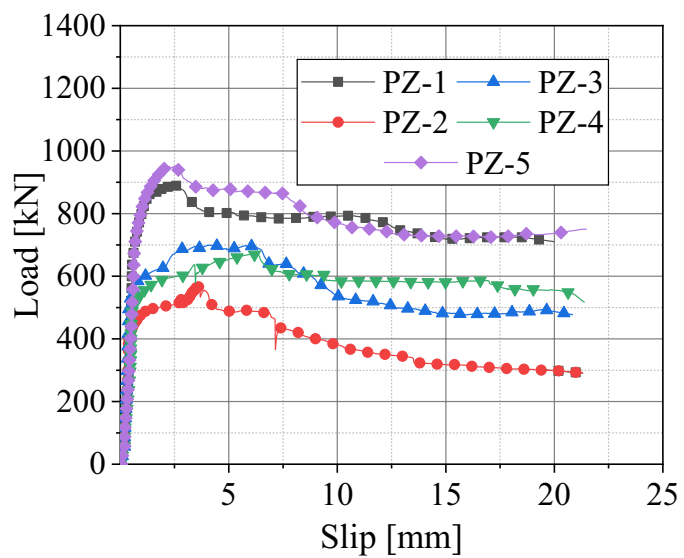

(b) Load-slip curves of PZ shear connectors

Figure 10. Load-slip curves of specimens.

\begin{tabular}{|c|c|c|c|c|c|c|c|}
\hline Specimen & $P_{u}(\mathrm{kN})$ & $\delta_{u}(\mathrm{kN})$ & $P_{R k}(\mathrm{kN})$ & $P_{R d}(\mathrm{kN})$ & $\delta_{d}(\mathrm{kN})$ & $K_{s}\left(\mathrm{kN} \mathrm{mm}^{-1}\right)$ & $D_{c}$ \\
\hline PBL-1 & 116.4 & 4.817 & 104.8 & 83.8 & 0.667 & 125.6 & 7.2 \\
\hline PBL-2 & 219.2 & 8.233 & 197.3 & 157.8 & 0.725 & 217.6 & 11.4 \\
\hline PBL-3 & 200.2 & 7.393 & 180.2 & 144.1 & 0.761 & 189.4 & 9.7 \\
\hline PZ-1 & 428.3 & 10.786 & 385.5 & 308.4 & 0.546 & 564.8 & 19.8 \\
\hline $\mathrm{PZ}-2$ & 283.8 & 4.359 & 255.4 & 200.3 & 0.379 & 528.5 & 11.5 \\
\hline PZ-3 & 333.1 & 7.873 & 299.8 & 239.8 & 0.403 & 595.0 & 19.5 \\
\hline $\mathrm{PZ}-4$ & 318.8 & 9.451 & 286.9 & 229.5 & 0.393 & 584.0 & 24.0 \\
\hline PZ-5 & 459.7 & 7.938 & 413.7 & 331.0 & 0.643 & 514.8 & 12.3 \\
\hline
\end{tabular}

Table 4. Static mechanical property indexes of tested shear connectors.

is the most obvious at A1 and B1 (lower part of the steel dowel). The strain increases rapidly with the increase of load. A1 and B1 are regions of stress concentration. The strain changes at A3 and B3 are relatively insignificant.

As shown in Fig. 12, the transversal reinforcement strain was negligible during the initial loading. D1 was the closest to the loading point among all strain measuring points, followed by D2 and D3. It can be claimed that as the load increases, the concrete pins are gradually crushed, and the transversal reinforcement begins to take the load, resulting in a sharp increase in the strain. The results showed a gradual bend of the transversal reinforcement. For the PBL-2 specimen at a load of $920 \mathrm{kN}$, the microstrains at points D1, D2, and D3 were 880,655 and 435 , respectively. Moreover, when the load of PBL-3 was $840 \mathrm{kN}$, the microstrain values of 660,490, and 320 were measured at points D1, D2, and D3, respectively. The load-strain curve of D1 had a more significant change than other measured points. This showed that the concrete tenon at D1 was crushed first, and the transversal 


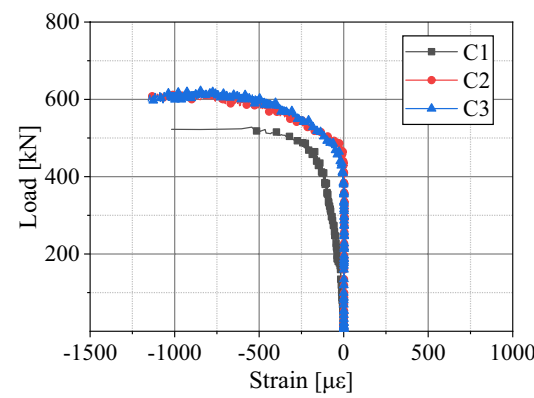

(a) PBL-1

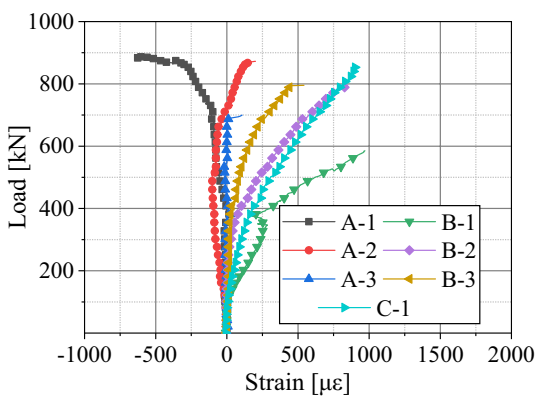

(d) PZ-1

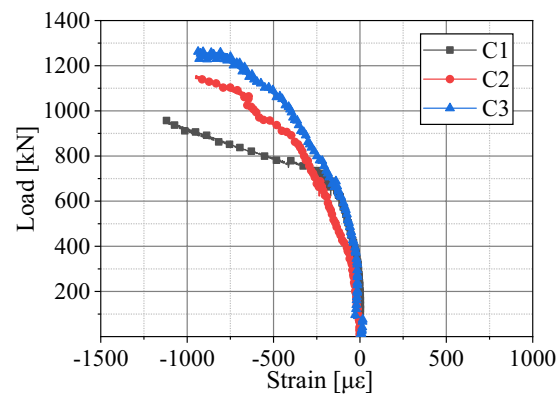

(b) PBL-2

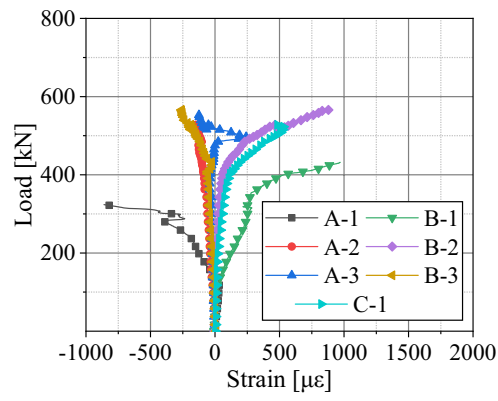

(e) PZ-2

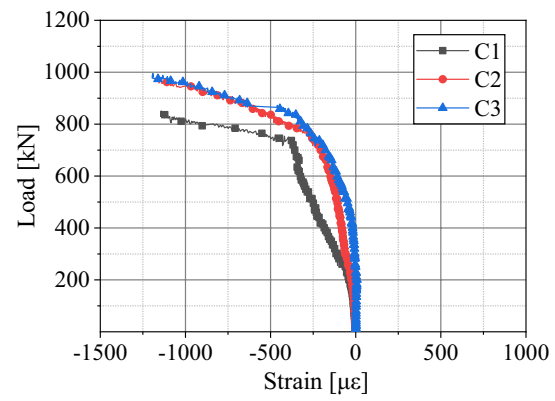

(c) PBL-3

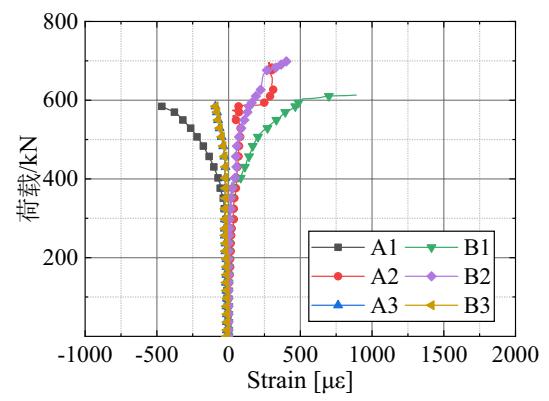

(f) PZ-3

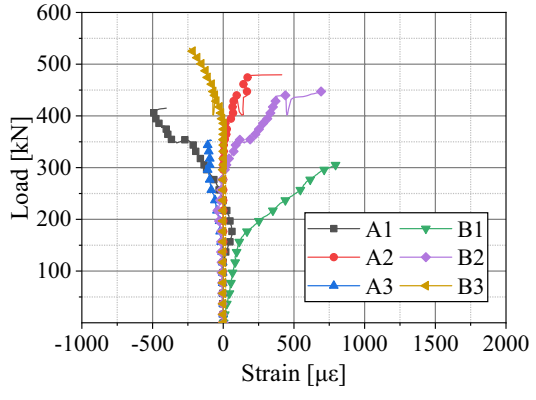

(g) PZ-4

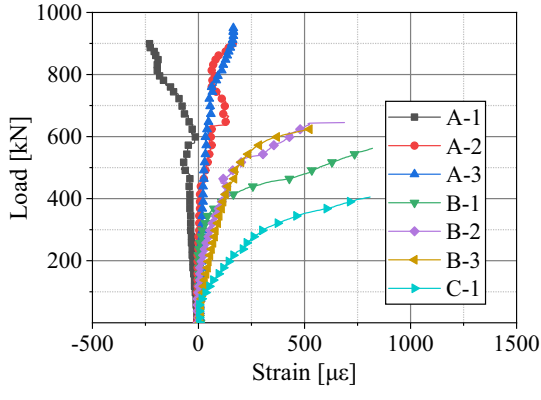

(h) PZ-5

Figure 11. Load-strain curves of steel dowels.

reinforcement was stressed earlier. Comparing the PBL-2 and PBL-3 specimens, the PBL-3 showed higher values of initial strain of the transversal reinforcement. The adhesion and friction between the concrete and the steel plate at the initial loading stage play an important role in resisting the load. As the PBL-2 was not coated with butter, lower values of strain were observed. For specimens with PZ shape composite dowel shear connectors, when the load value was $0.7 P_{\mathrm{u}}$, the microstrain value of point D1 was about four times that of point D2. The transversal reinforcement close to the loading point was mainly used to bear the load while providing a pinning force was the primary use of the transversal reinforcement far away from the loading point.

\section{Design recommendations}

Shear bearing capacity. Studies have shown three types of possible failure modes in PZ shape composite dowel shear connectors under load ${ }^{29-31}$. Different failure modes have different calculation formulas for bearing capacity.

For small openings between the dowels and large steel plate thicknesses, the dominating failure mode is the double plane shearing of the concrete dowel. Therefore, the main parameters for the load-bearing capacity are the shear area of the concrete dowel and the shear strength of the concrete. With large openings, the two shear planes merge together, which is taken into account by a geometry-dependent reduction factor $\eta_{D}$. The bearing capacity is expressed by:

$$
p_{s h, k}=\eta_{D} \cdot e_{x}^{2} \cdot \sqrt{f_{c k}} \cdot\left(1+\rho_{D}\right)
$$




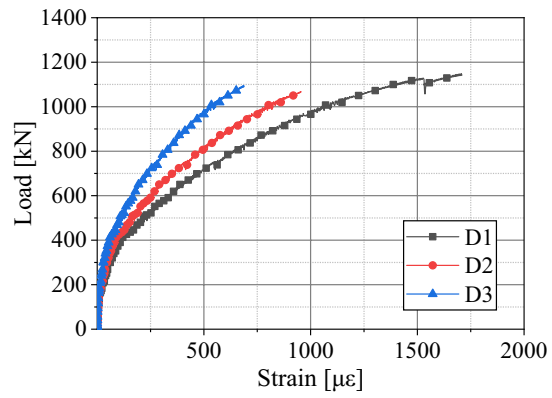

(a) PBL-2

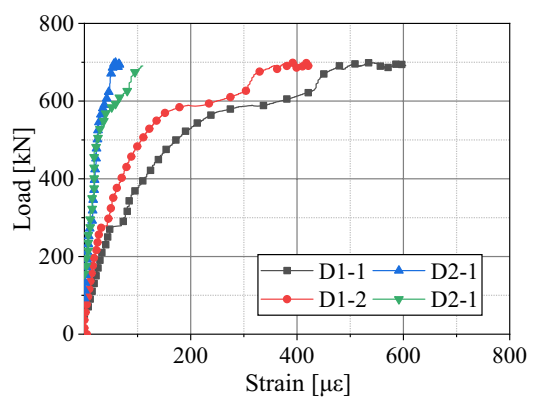

(d) PZ-3

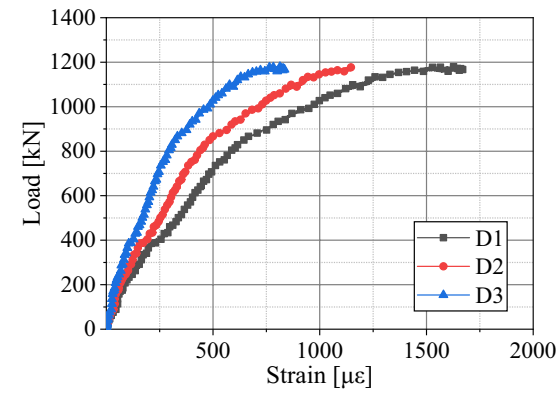

(b) PBL-3

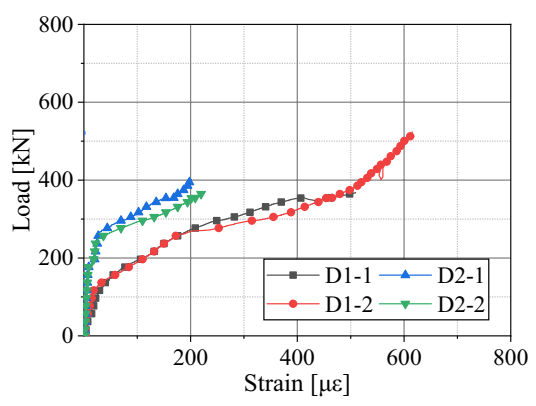

(e) PZ-4

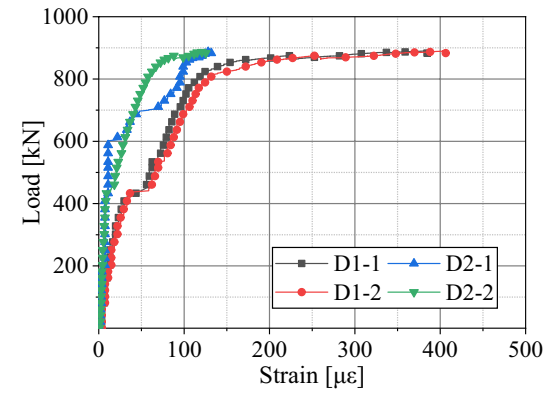

(c) PZ-1

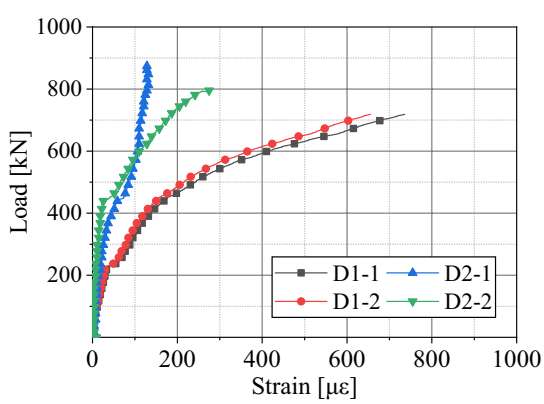

(f) PZ-5

Figure 12. Load-strain curves of transversal reinforcement.

where $\eta_{D}=2-e_{x} / 400, \rho_{\mathrm{D}}=\left(E_{s} \cdot A_{b}\right) /\left(E_{c m} \cdot A_{D}\right), A_{b}$ is the cross-sectional area of transversal reinforcement, $A_{D}$ is the shear area of concrete dowel $\left(A_{D}=0.13 e_{x}^{2}\right), E_{s}$ is the elastic modulus of transversal reinforcement, $E_{c m}$ is the elastic modulus of concrete, and $f_{c k}$ is compressive strength of concrete.

According to the experimental results, the failure mode of $\mathrm{PZ}$ shape composite dowel shear connectors in this test is concrete shear failure. Since this test design is with a single dowel, the factor $\eta_{D}$ is not considered in the formula. According to Formula (2), the characteristic bearing capacity is $P_{s h, k}=329.7 \mathrm{kN}$. Using PZ-3 and PZ-4 as examples, according to the test results, the characteristic bearing capacities of PZ-3 and PZ-4 are $299.8 \mathrm{kN}$ and $286.9 \mathrm{kN}$, respectively. The values calculated by the theoretical formula are larger than the experimental results.

The thickness and spacing of steel dowels are large in prefabricated composite beams. The influence of stirrups in composite beams on bearing capacity is also significant. The bearing capacity depends on the structure. The theoretical formula for prefabricated composite beams does not apply to composite bridge decks. Therefore, it is necessary to establish a formula for calculating the bearing capacity of PZ shape composite dowel shear connectors with elliptic holes in corrugated steel-concrete composite bridge decks.

The bearing capacity of PZ shape composite dowel shear connectors with elliptical holes is mainly dependent on the composite dowel and concrete tenon with elliptical holes. The bearing capacity can be expressed by:

$$
p_{s h, k}=p_{c}+p_{e}
$$

Refer to the existing formula for the bearing capacity of composite dowels $\left(p_{c}\right)$, we introduce a reduction factor $\varphi_{c}$. According to the characteristic bearing capacity of PZ-3 and PZ-4, the value of $\varphi_{c}$ is 0.889 . Then the bearing capacity of the composite dowel part is:

$$
p_{c}=0.889 e_{x}^{2} \cdot \sqrt{f_{c k}}\left(1+\rho_{D}\right)
$$

According to the literature ${ }^{32}$, the bearing capacity of the concrete tenon $\left(p_{e}\right)$ can be expressed by:

$$
p_{e}=2 \varphi_{e} A_{e} \sqrt{f_{c k}}
$$

where $A_{e}$ is the area of the elliptical opening. $A_{e}=\pi a b$, where a and $\mathrm{b}$ are the long and short semi-axes of the elliptical hole. $\varphi_{e}$ is the influence coefficient. According to the PZ-1 and PZ-3 tests, the characteristic bearing capacity of small elliptical holes can be calculated as $86 \mathrm{kN}$. According to the PZ-4 and PZ-5 tests, the characteristic bearing capacity of large elliptical holes can be calculated as $127 \mathrm{kN}$. By substituting into Formula (6), the value of $\varphi_{e}$ is 4.738 . Therefore, bearing capacity of the concrete tenon is

$$
p_{e}=9.476 A_{e} \sqrt{f_{c k}}
$$

In summary, the bearing capacity formula of PZ shape composite dowel shear connectors with elliptical holes in corrugated steel-concrete composite bridge decks is:

$$
p_{s h, k}=0.889 e_{x}^{2} \cdot \sqrt{f_{c k}}\left(1+\rho_{D}\right)+9.476 \pi a b \sqrt{f_{c k}}
$$




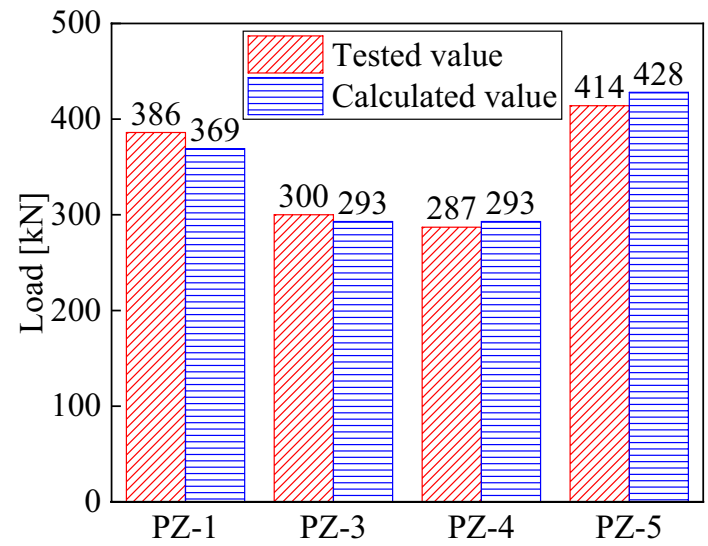

Figure 13. Comparison results of calculated and tested values.

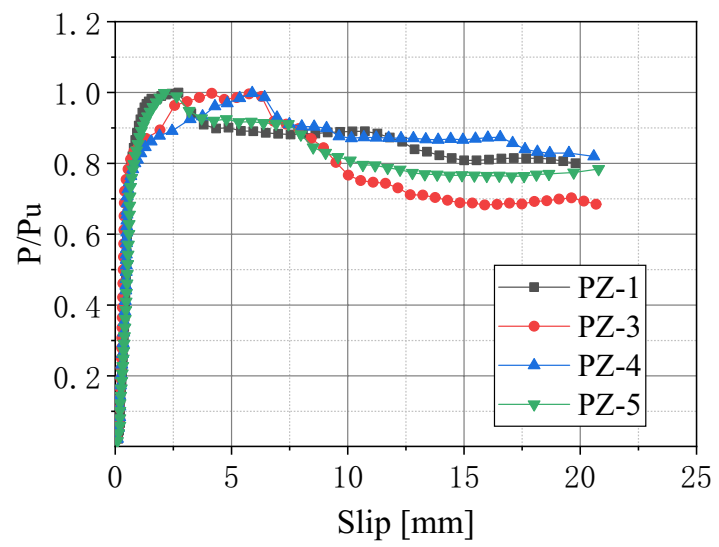

Figure 14. Dimensionless load-slip curve.

According to the proposed theoretical calculation formula, the shear capacity of four tested specimens with perforated transversal reinforcement was calculated. The comparison between the calculated results and the test results is shown in Fig. 13. The errors between calculation and tested values were less than 5\%, suggesting good agreement between theoretical and experimental values.

Load-slip curve. The load-slip curves of the PZ-1, PZ-3, PZ-4, and PZ-5 specimens were treated as being dimensionless, which are shown in Fig. 14.

It can be seen from Fig. 14 that there are two distinct areas in the dimensionless load-slip curves: rising and falling sections. The logarithmic function can be used to describe both the rising and the falling parts. The fitting curve can be expressed by:

$$
P / P_{\mathrm{u}}=a \ln (S)+b
$$

The linear regression method was used to fit the dimensionless load-slip curves of PZ-1, PZ-3, PZ-4, and PZ-5 specimens, and to understand the load-slip relationship of the shear connector in the two areas. Given this, the $a$ and $b$ variables were calculated as follows: in the ascending section $a=0.339$ and $b=0.810$, and for the descending section $\mathrm{a}=-0.078$ and $\mathrm{b}=1.041$. Therefore, the calculation formula of the load-slip curve of $\mathrm{PZ}$ shape composite dowel shear connector is described as:

$$
P / P_{u}= \begin{cases}0.339 \ln (S)+0.810 & 0<S \leq S_{u} \\ -0.078 \ln (S)+1.041 & S>S_{u}\end{cases}
$$

where $P_{\mathrm{u}}$ is the ultimate bearing capacity and $S_{\mathrm{u}}$ is the corresponding slip amount under the ultimate bearing capacity.

Figure 15 compares the fitted curve and the curve obtained from the test results. It can be seen from Fig. 15 that, the curve fitted according to the proposed formula is in good agreement with the one obtained from the test results. However, the calculated stiffness of the plastic region falls slightly below the measured one. Therefore, 


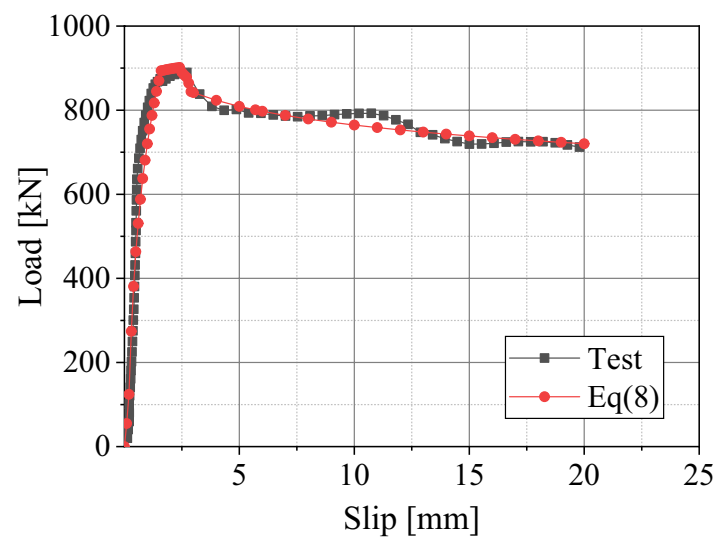

(a) PZ-1

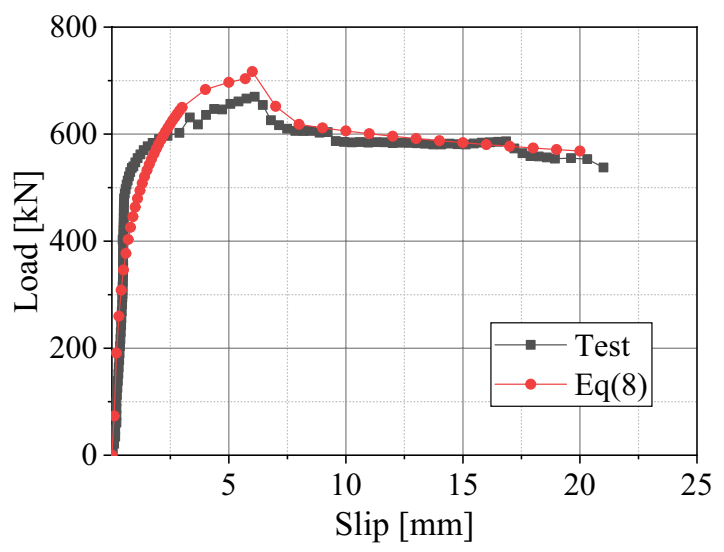

(a) PZ-4

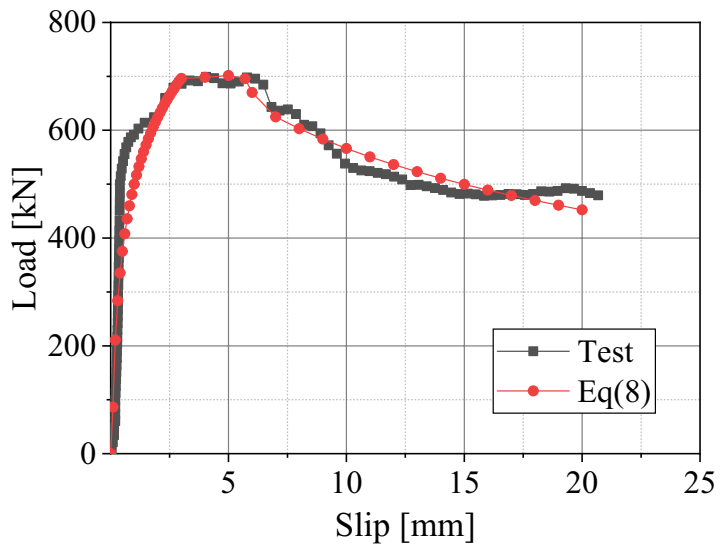

(b) PZ-3

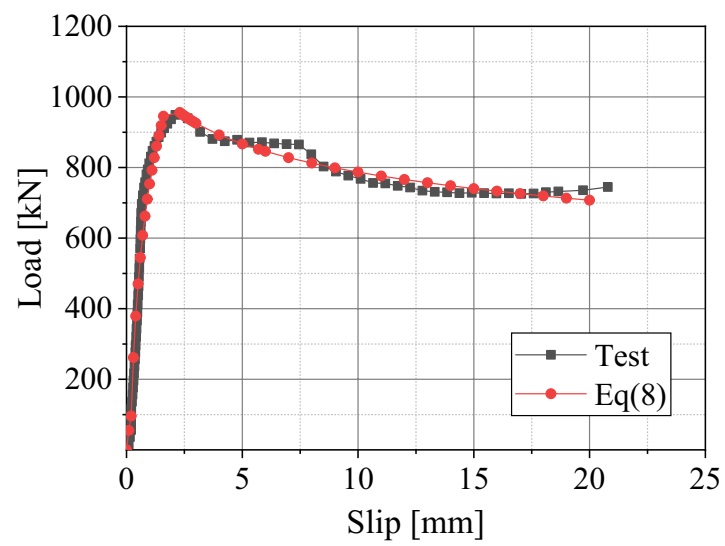

(b) PZ-5

Figure 15. Comparison of load-slip curves between the test results and the fitting formula.

the load-slip curve proposed in this study accurately reflects the overall characteristics of the load-slip curve of the PZ shape composite dowel shear connectors.

Different mechanical features of a shear connector, such as the bearing capacity, shear stiffness and deformation capacity can be obtained from the load-slip curve, and is the most important mechanical feature of the shear connector. Transversal reinforcement and concrete tenons determine the bearing capacity of a PZ shape composite dowel shear connector. The bearing capacity provided by concrete tenon is affected by various factors such as dowel size, concrete strength and constraint state. In contrast, for the transversal reinforcement, the bearing capacity varies significantly under different constraints. PZ shape composite dowel shear connectors are known to have a complex bearing mechanism. The calculated values for the bearing capacity are quite different, with the measured ones in the push-out test, due to the different factors considered by researchers. The theoretical formulas in this work are applicable to the PZ shape composite dowel shear connectors with small size and weak constraints in the corrugated steel-concrete composite bridge deck. However, as the experiments were performed only once, there was no test redundancy. Further studies with more tests are required to achieve reliable results.

\section{Conclusion}

The push-out tests of PBL and PZ shape composite dowel shear connectors with elliptical holes in corrugated steel-concrete composite bridge decks were conducted, and their mechanical behavior was also studied. Based on the test results in this paper, several conclusions can be drawn and are summarized as follows.

(1) The two exhibited failure forms were shear failure of concrete and ductile failure of shear connectors. In the case of failure, there was no significant strain change in the steel dowel and elliptical hole of the PZ shape shear connector or the round hole of the PBL shear connector. But there was obvious deformation in the transversal reinforcement in both designs.

(2) Both types of shear connectors had the same load-slip tendency. Transversal reinforcement is an important factor affecting bearing capacity and shear stiffness. The ultimate bearing capacity of shear connectors can be significantly increased by opening elliptical holes. But this will also reduce the shear stiffness. The shear connector height has little effect on the bearing capacity. 
(3) In corrugated steel-concrete composite bridge decks, PZ shape composite dowel shear connectors are superior to PBL shear connectors in bearing capacity, shear stiffness, and ductility. Due to the structural characteristics of the $\mathrm{PZ}$ shape shear connector, it is easy to penetrate the transversal reinforcement.

(4) The comparative analysis of the existing theoretical calculation results and experimental results shows that the theoretical calculation results are slightly higher. The calculation formula of PZ shape composite dowel shear connectors in composite beams in European technical standards is not applicable to composite bridge panels. In this paper, based on the existing research and considering engineering practice, a formula for calculating the bearing capacity of $\mathrm{PZ}$ shape composite dowel shear connectors with elliptic holes in corrugated steel-concrete composite bridge decks was proposed. Based on the characteristics of load-slip curves obtained from experiments, two formulas were proposed for the load-slip curves and were used to fit a curve to the experimental data. The results calculated by the formulas agreed well with the experimental results. These two formulas may be used to guide the design of shear connections in corrugated steel-concrete composite bridge decks.

In the present paper, an experimental study was done on the behavior of PZ shape composite dowel shear connectors, yet the theoretical investigations were limited. A further detailed analysis of the FEM simulations will be presented in a separate study.

Received: 9 October 2021; Accepted: 24 January 2022

Published online: 14 February 2022

\section{References}

1. Yang, M. Y. Research on Mechanical Properties of Corrugated Steel Plate-UHPC Composite Bridge Deck under Positive Bending Moment (Southwest Jiaotong University, 2019).

2. Su, Q. T., Tian, L., Zeng, M. G., Shao, C. Y. \& Chen, L. Research on basic performance of composite bridge decks with orthotropic corrugated steel plates and concrete. Eng. Mech. 33, 138-142 (2016).

3. Li, X., Zheng, X. Y., Ashraf, M. \& Li, H. T. The longitudinal shear bond behavior of an innovative laminated fiber reinforced composite slab. Constr. Build. Mater. 215, 508-522 (2019).

4. Kong, F. L., Huang, P. M., Han, B., Wang, X. Z. \& Liu, C. Q. Experimental study on behavior of corrugated steel-concrete composite bridge decks with MCL shape composite dowels. Eng. Struct. 227, 111399 (2021).

5. Santos, L. R. D., Caldas, R. B., Grilo, L. F., Carvalho, H. \& Fakury, R. H. Design procedure to bearing concrete failure in concretefilled steel tube columns with bolted shear connectors. Eng. Struct. 232, 111910 (2021).

6. Di, J., Zou, Y., Qin, F. J. \& Zhou, X. H. Research on mechanical performance of large perfobond connectors with strong confinement. China J. Highw. Transp. 31, 38-48, 58 (2018).

7. He, S. H., Guan, P. D., Wang, Q., Fang, Z. \& Mosallam, A. Investigation on structural performance of perfobond strip connector group in steel-concrete joints. Eng. Struct. 242, 112571 (2021).

8. Yang, Y. \& Chen, Y. Experimental study on the shear capacity of PBL shear connectors. China Eng. Mech. 35, 89-96 (2018).

9. Zhang, Q. H. et al. Internal force transfer effect-based fatigue damage evaluation for PBL shear connector groups. J. Constr. Steel Res. 148, 469-478 (2018).

10. Cardoso, H. D. S., Aguiar, O. P., Caldas, R. B. \& Fakury, R. H. Composite dowels as load introduction devices in concrete-filled steel tubular columns. Eng. Struct. 219, 110805 (2020).

11. Classen, M., Gallwoszus, J. \& Stark, A. Anchorage of composite dowels in UHPC under fatigue loading. Struct. Concrete. 17, 183-193 (2016).

12. Classen, M. \& Gallwoszus, J. Concrete fatigue in composite dowels. Struct. Concrete. 17, 63-73 (2016).

13. Kożuch, M. \& Lorenc, W. Stress concentration factors of shear connection by composite dowels with MCL shape. Arch. Civ. Mech. Eng. 19, 32-46 (2019).

14. Classen, M. \& Hegger, J. Shear-slip behaviour and ductility of composite dowel connectors with pry-out failure. Eng. Struct. 150, $428-437$ (2017).

15. Classen, M. \& Hegger, J. Assessing the pry-out resistance of open rib shear connectors in cracked concrete-Engineering model with aggregate interlock. Eng. Struct. 148, 254-262 (2017).

16. Lechner, T., Gehrlein, S. \& Fischer, O. Structural behavior of composite dowels in thin UHPC-elements. Steel Constr. 9, 132-137 (2016).

17. Lorenc, W., Kożuch, M. \& Rowiński, S. The behaviour of puzzle-shaped composite dowels-Part I: Experimental study". J. Constr. Steel Res. 101, 482-499 (2014).

18. Lorenc, W., Kożuch, M. \& Rowiński, S. The behaviour of puzzle-shaped composite dowels-Part II: Theoretical investigations. J. Constr. Steel Res. 101, 500-518 (2014).

19. Lacki, P., Kasza, P. \& Adamus, K. Optimization of composite dowels shape in steel-concrete composite floor. Compos. Struct. 222, 110902 (2019).

20. Lacki, P., Derlatka, A., Kasza, P. \& Gao, S. Numerical study of steel-concrete composite beam with composite dowels connectors. Comput. Struct. 255, 106618 (2021).

21. Lorenc, W. The model for a general composite section resulting from the introduction of composite dowels. Steel Constr. 10, 154-167 (2017).

22. Classen, M. Limitations on the use of partial shear connection in composite beams with steel T-sections and uniformly spaced rib shear connectors. J. Constr. Steel Res. 142, 99-112 (2018).

23. Classen, M., Herbrand, M. \& Stark, A. Shear force-slip characteristic of composite dowels with steel failure. Bauingenieur. 92, 237-244 (2017).

24. Lorenc, W. Concrete failure of composite dowels under cyclic loading during full-scale tests of beams for the "Wierna Rzeka" bridge. Eng. Struct. 209, 110199 (2020).

25. Classen, M., Herbrand, M., Adam, V., Kueres, D. \& Sarac, M. Puzzle-shaped rib shear connectors subjected to combined shear and tension. J. Constr. Steel Res. 145, 232-243 (2018).

26. Kożuch, M. \& Rowiński, S. Elastic behaviour of the steel part of a shear connection with MCL composite dowels. Steel Constr. 9, 107-114 (2016).

27. Xiao, L., Wei, X. \& Qiang, S. Z. Comparative study on two kinds of push-out tests of PBL shear connectors. China Civil Eng. J. 46, $70-80$ (2013).

28. Eurocode4: Design of composite steel and concrete structures-Part 1-1: General rules and rules for buildings: EN 1994-1-1 (2004; 2012). 
29. Feldmann, M., Kopp, M. \& Pak, D. Composite dowels as shear connectors for composite beams-background to the German technical approval. Steel Costr. 9, 80-88 (2016).

30. Kopp, M. et al. Composite dowels as shear connectors for composite beams-background to the design concept for static loading. J. Constr. Steel Res. 147, 488-503 (2018).

31. German Institute for Building Technology (DIBT): Technical approval for Composite Dowels, no. Z-26.4-56, Berlin (2018).

32. Oguejiofor, E. C. \& Hosain, M. U. Numerical analysis of push-out specimens with perfobond rib connectors. Comput. Struct. 62, 617-624 (1997).

\section{Acknowledgements}

This work was supported by the National Natural Science Foundation of China (51878058).

\section{Disclaimer}

We declare that we have no financial and personal relationships with other people or organizations that can inappropriately influence our work, there is no professional or other personal interest of any nature or kind in any product, service and/or company that could be construed as influencing the position presented in, or the review of, the manuscript entitled.

\section{Author contributions}

Pingming $\mathrm{H}$ and Fanlei K carried out the push-out tests, researched the date and wrote the manuscript, Kuihua $\mathrm{M}$ designed the experiments, Junlong $\mathrm{H}$ and Xiaolong $\mathrm{L}$ contributed to the figures and tests.

\section{Competing interests}

The authors declare no competing interests.

\section{Additional information}

Correspondence and requests for materials should be addressed to J.H. or F.K.

Reprints and permissions information is available at www.nature.com/reprints.

Publisher's note Springer Nature remains neutral with regard to jurisdictional claims in published maps and institutional affiliations.

Open Access This article is licensed under a Creative Commons Attribution 4.0 International License, which permits use, sharing, adaptation, distribution and reproduction in any medium or format, as long as you give appropriate credit to the original author(s) and the source, provide a link to the Creative Commons licence, and indicate if changes were made. The images or other third party material in this article are included in the article's Creative Commons licence, unless indicated otherwise in a credit line to the material. If material is not included in the article's Creative Commons licence and your intended use is not permitted by statutory regulation or exceeds the permitted use, you will need to obtain permission directly from the copyright holder. To view a copy of this licence, visit http://creativecommons.org/licenses/by/4.0/.

(c) The Author(s) 2022 